\title{
Relationship between CYP7A1 -204A > C polymorphism with gallbladder stone disease and serum lipid levels: a meta-analysis
}

\author{
Qiang Cai ${ }^{1+}$, Zhen-Qiang Wang ${ }^{1 \dagger}$, Qu Cai ${ }^{1}$, Chen Li ${ }^{1}$, Er-Zhen Chen ${ }^{2}$ and Zhao-Yan Jiang ${ }^{1 *}$
}

\begin{abstract}
Background: The CYPTA1 gene polymorphism has been reported to be associated with gallbladder stone disease (GSD) and serum lipid levels, but the results were inconsistent. This meta-analysis aimed to evaluate the influence of the -204A > C polymorphism in the promoter of CYP7A1 gene on the GSD and serum lipid levels.

Methods: According to inclusion/exclusion criteria, eligible studies on CYP7A1 gene -204A > C polymorphism of serum lipid levels and the risk of GSD were retrieved. Depending on the between-study heterogeneity, the fixed- or random-effects model was applied, and the data were analyzed using the RevMan software (V5.2).

Results: Five studies totaling 830 GSD patients and 882 healthy controls were used to evaluate the relation of CYP7A1 -204A > C polymorphism with GSD. Overall comparison of alleles A with C in all study population yielded $5 \%$ but non-significant increased risk of GSD (OR $=1.05,95 \% \mathrm{Cl}$ : $0.91-1.22, \mathrm{P}=0.48)$. Subgroup analysis by ethnic differences did not show any association between CYP7A1-204A > C polymorphism and GSD either. Four studies totaling 802 cases and 691 controls were used to assess the relation of CYP7A1 -204A >C polymorphism with serum lipid levels. All the subjects were from the Asian population. The pooled effects indicated that AC genotype had higher levels of TG than AA ( $M D=-0.42,95 \% \mathrm{Cl}:-0.76--0.08, P=0.01)$. CC genotype in cases had higher levels of $\mathrm{TC}(\mathrm{MD}=0.65,95 \% \mathrm{Cl}: 0.25-1.05, \mathrm{P}=0.001)$ and $\mathrm{LDL}-\mathrm{C}(\mathrm{MD}=0.40,95 \% \mathrm{Cl}: 0.06-0.73, \mathrm{P}=0.02)$ than $\mathrm{AA}$, AA $(\mathrm{MD}=-0.35,95 \% \mathrm{Cl}:-0.60--0.10, \mathrm{P}=0.007)$ and $\mathrm{AC}(\mathrm{MD}=-0.35,95 \% \mathrm{Cl}:-0.61--0.08, \mathrm{P}=0.01)$ genotypes in controls had higher levels of TC than CC, and AA genotype in controls had higher levels of HDL-C than CC $(\mathrm{MD}=-0.15,95 \% \mathrm{Cl}:-0.21--0.09, \mathrm{P}<0.00001)$.
\end{abstract}

Conclusions: The CYP7A1 -204A > C polymorphism is significantly associated with serum lipid levels in Asian population, but not gallbladder stone disease.

Keywords: Gallbladder stone disease, Cholesterol 7a-hydroxylase, Serum lipids, Polymorphism, Meta-analysis

\section{Introduction}

Gallbladder stone disease (GSD) is one of the most common diseases in many countries. The formation of GSD is multi-factorial, with a complex interaction between the environment factors and multiple susceptible genes [1]. Data from the Swedish Twin Registry showed that the contribution of hereditary factors to symptomatic GSD accounts for $25 \%$ [2].

\footnotetext{
* Correspondence: zhaoyanjiang@gmail.com

${ }^{\dagger}$ Equal contributors

'Department of Surgery, Shanghai Institute of Digestive Surgery, Ruijin Hospital, Shanghai JiaoTong University School of Medicine, 200025 Shanghai, China

Full list of author information is available at the end of the article
}

Oversaturatation of biliary cholesterol is the requisite biochemical defect for the formation of GSD [3]. This pathophysiological change is induced by either hypersecretion of biliary cholesterol or decreased secretion of bile acids. Both the cholesterol secreted into bile and the bile acids converted from cholesterol in the liver are involved in the regulating cholesterol homeostasis. Cholesterol $7 \alpha$-hydroxylase (CYP7A1) is the rate-limiting enzyme of hepatic bile acid synthesis. A rare mutation of CYP7A1 gene was reported to account for the incidence of gallstone disease as well as familial hypercholesterolemia in a family [4]. Various genetic variations have also been reported in CYP7A1 gene [5,6]. The polymorphism of

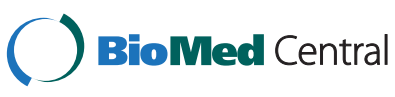

(c) 2014 Cai et al.; licensee BioMed Central Ltd. This is an Open Access article distributed under the terms of the Creative Commons Attribution License (http://creativecommons.org/licenses/by/4.0), which permits unrestricted use, distribution, and reproduction in any medium, provided the original work is properly credited. The Creative Commons Public Domain Dedication waiver (http://creativecommons.org/publicdomain/zero/1.0/) applies to the data made available in this article unless otherwise stated. 
-204A > C (rs3808607) in the promoter of CYP7A1 gene was reported to affect its enzyme activity [7]. A number of studies have been focused on the association between the $-204 \mathrm{~A}>\mathrm{C}$ polymorphism and metabolic disorders of cholesterol and bile acid, including hypercholesterolemia, hypertriglyceridemia and GSD [8-13]. However, the results are inconsistent and inconclusive due to different study design, population, etc. Therefore, we performed this meta-analysis to evaluate the relation of CYP7A1 -204A > C polymorphism with GSD as well as serum lipid levels.

\section{Materials and methods Search strategy}

We conducted a systematic publication search that published in English or Chinese via pubic database PubMed, Embase, ISI Wed of Knowledge, China Biological Medicine (CBM) and China National Knowledge
Infrastructure (CNKI) up to February 2014 using the following terms: "Cholesterol $7 \alpha$-hydroxylase", "CYP7A1", "rs3808607 (-204A > C) polymorphism", "gallbladder stone disease", "dyslipidemia" and "serum lipid levels". The search was restricted to humans. All eligible studies were retrieved and the full text of the articles was examined to make sure the data of interest were included. If multiple reports from the same patients were found, only the publication with the most complete data set was included.

\section{Inclusion and exclusion criteria}

Studies that we identified were required to meet the following criteria: (1) study on -204A > C polymorphism of CYP7A1 gene, serum lipid levels and the risk of GSD; (2) case-control study that used either hospital-based or population-based designs; (3) reporting at least one relevant outcomes of association between genotype and
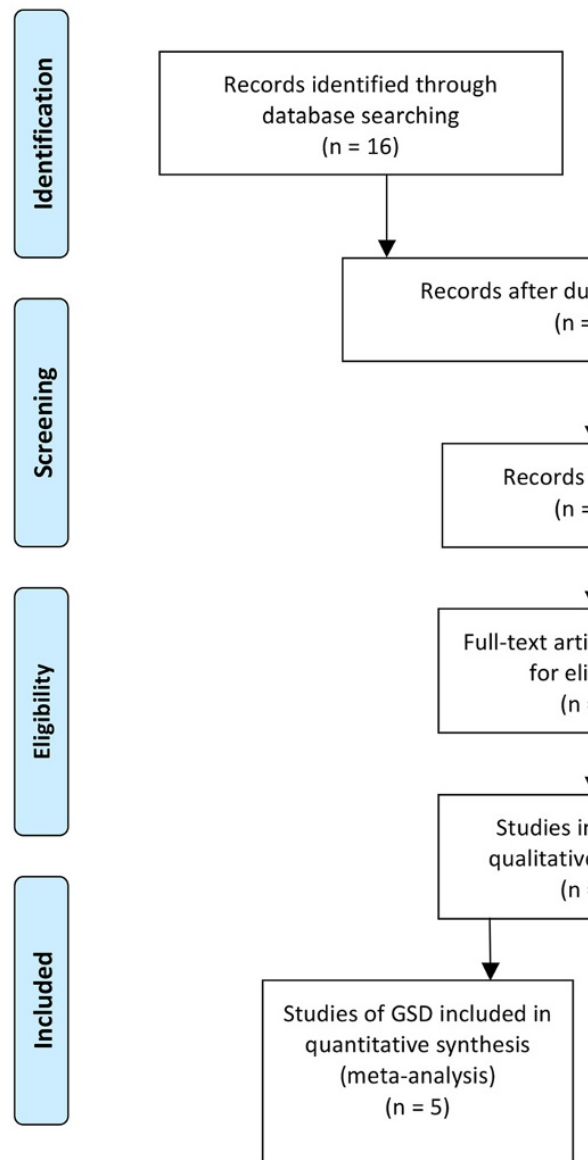

Additional records identified through other sources $(n=0)$

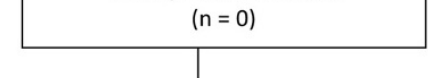

licates removed $n=15)$
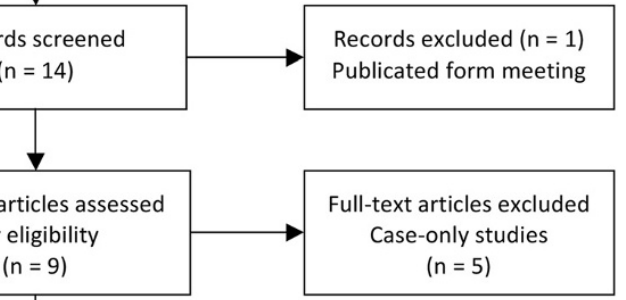

$(n=9)$

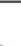

Studies included in $=9)$

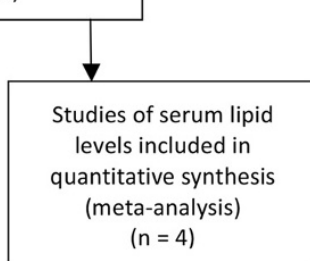

Figure 1 Flow diagram of search strategy and study selection. 


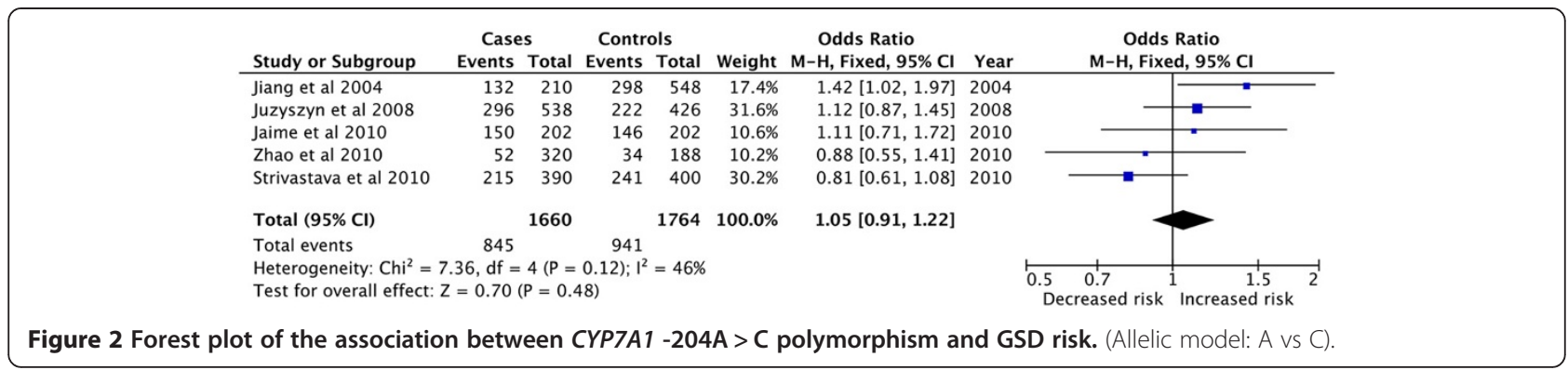

serum lipid levels and the risk of GSD, serum lipid levels including total cholesterol (TC), high-density lipoprotein cholesterol (HDL-C), low-density lipoprotein cholesterol (LDL-C), and triglycerides (TG). Studies were excluded if they were case-only studies, case reports, or published abstracts from meeting.

\section{Extracted information}

Two investigators (QC and ZQW) independently extracted the following information from all selected articles: first author, year, country, ethnicity, eligible subjects, study design, methods to diagnosis, genotyping information (genotyping method, number of genotypes, genotype distribution in cases and controls), association between genotypes and serum lipid parameters and the risk of GSD, etc. Ethnic backgrounds were categorized as Caucasian or Asian. The units of measurements used in this study were transformed into the standard measurements units.

\section{Statistical analysis}

Before estimating the relationship between the CYP7A1 $-204 \mathrm{~A}>\mathrm{C}$ polymorphism and GSD and serum lipid levels, we tested whether the genotype frequencies of the controls were in Hardy-Weinberg equilibrium (HWE) using a $\chi^{2}$ test $(P>0.05)[14]$. We carried out statistical analysis by the software Review Manager (V5.2) for Mac Os X. Continuous variables were expressed as mean difference (MD) with 95\% confidence intervals (CI). Dichotomous variables were expressed as odd ratio (OR) with 95\% CI. Subgroup analysis for ethinicity (Asian and Caucasian) and population (case and control) was conducted. The chi-square test based on $Q$ test and $I^{2}$ statistics were used to assess the hererogeneity among studies [15-17]. When the $Q$ test was significant $(\mathrm{P}<0.05)$ or $I^{2}>$ $50 \%$, indicating the presence of heterogeneity, a randomeffects model (the DerSimonian \& Laird method) was used [18]; otherwise, the fixed-effects model (the MantelHaenszel method) was used [19]. If enough studies were identified, funnel plots were to be used to investigate reporting biases.

\section{Results}

\section{Studies and populations}

The literature search identified 16 potentially relevant papers. Seven papers were excluded and 9 papers (5 in English [5,11,12,20,21], 4 in Chinese [22-25]) were included finally. A flow diagram of the study selection process is presented in Figure 1. All of the studies had been approved by the Ethics Committee of their affiliations, in accordance with the Helsinki Declaration of 1975 as revised in 1983, and all subjects had given informed consent. The present study was approved by the Ethics Committee of the Ruijin Hospital, Shanghai JiaoTong University School of Medicine. Five of the eligible studies including 830 gallbadder stone disease patients and 882 controls were used to evaluate the relation of CYP7A1 -204A > C polymorphism with GSD [5,11,12,21,23]. Four of the eligible studies including 802 cases and 691 controls were used to assess the association between CYP7A1 -204A > C polymorphism and serum lipid levels $[20,22,24,25]$. Many studies have proved that serum lipid concentrations are strongly correlated to the risk of coronary artery disease (CAD), two papers contained the data of CAD was elected for the meta-analysis [20,24]. The main characteristics of each study are presented in Additional file 1: Table S1.

\section{Analyses of the risk of GSD}

In allelic model, the eligible compared groups were pooled with the fixed-effects models and the comparison showed that the CYP7A1 -204A allele was related to a nonsignificant $5 \%$ increased risk of GSD $(\mathrm{OR}=1.05$, 95\% CI: $0.91-1.22, \mathrm{P}=0.48$ ) (Figure 2). No significance was observed in genotypic models for comparisons of

Table 1 Comparisons of A vs C in allele, genotype dominant and recessive models for GSD risk

\begin{tabular}{llll}
\hline Comparisons & Pooled OR (95\% Cl) & $\mathbf{Z}(\mathbf{P})$ & $\boldsymbol{I}^{\mathbf{2}} \mathbf{( \% )}$ \\
\hline A vs C & $1.05(0.91,1.22)$ & $0.70(0.48)$ & 46 \\
AA vs CC & $1.06(0.79,1.42)$ & $0.42(0.68)$ & 41 \\
AC vs CC & $0.92(0.70,1.21)$ & $0.60(0.55)$ & 0 \\
AA + AC vs CC & $0.97(0.76,1.25)$ & $0.22(0.82)$ & 12 \\
AA vs AC + CC & $1.15(0.92,1.43)$ & $1.25(0.21)$ & 31 \\
\hline
\end{tabular}




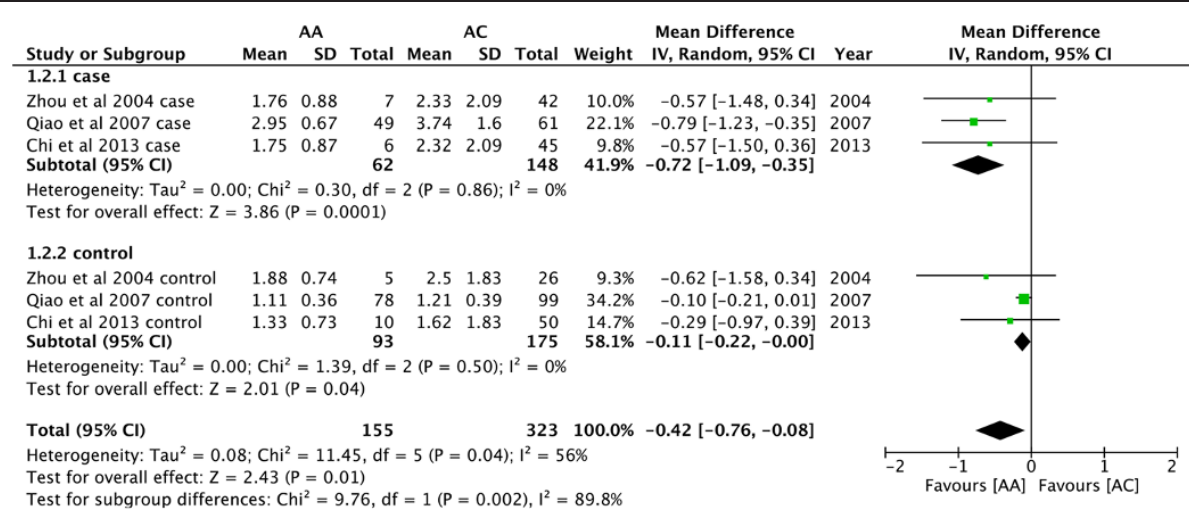

Figure 3 Forest plot of the association between CYP7A1 -204A > C polymorphism and serum TG levels. (Genetic model: AA vs AC).

AA $(\mathrm{OR}=1.06,95 \% \mathrm{CI}: 0.79-1.42, \mathrm{P}=0.68)$ and $\mathrm{AC}$ $(\mathrm{OR}=0.92,95 \% \mathrm{CI}: 0.70-1.21, \mathrm{P}=0.55)$ genotypes with $\mathrm{CC}$ genotype, respectively, as well as in dominant $(\mathrm{OR}=0.97,95 \% \mathrm{CI}: 0.76-1.25, \mathrm{P}=0.82)$ and recessive $(\mathrm{OR}=1.15,95 \% \mathrm{CI}: 0.92-1.43, \quad \mathrm{P}=0.21)$ models (Table 1).

Considering the ethnic differences might bias the overall association, we separated the studies in Asian and Caucasian. There was no significant change in all subgroups either (data not shown).

\section{Analyses of the serum lipid levels}

In the present study, we included four studies in which all the subjects were Asian population. As shown in Figure 3, the pooled effects indicated that AC genotype had higher levels of TG than AA ( $\mathrm{MD}=-0.42,95 \%$ CI: $-0.76-0.08, P=0.01)$. Meanwhile, the magnitude of association was largely strengthened in cases
$(\mathrm{MD}=-0.72,95 \% \mathrm{CI}:-1.09--0.35, \mathrm{P}=0.0001)$. As shown in Figure 4, AA genotype had higher levels of TC than CC in controls $(\mathrm{MD}=-0.35,95 \% \mathrm{CI}:-0.60--0.10, \mathrm{P}=0.007)$, but not in the recessive models in cases $(\mathrm{MD}=0.65,95 \%$ CI: $0.25-1.05, P=0.001)$. AC genotype had higher levels of $\mathrm{TC}$ than $\mathrm{CC}$ in controls $(\mathrm{MD}=-0.35,95 \%$ CI: $-0.61--0.08, P=0.01$; Figure 5 ). There was no significant difference in the levels of TC between AA and $\mathrm{AC}$ genotypes $(\mathrm{MD}=-0.09,95 \% \mathrm{CI}:-0.31-0.13, \mathrm{P}=0.40)$. Compared with $\mathrm{CC}$ genotype in controls, AA had higher levels of HDL-C (MD $=-0.15,95 \% \mathrm{CI}:-0.21--0.09$, $\mathrm{P}<0.00001$; Figure 6). For the comparison of LDL-C levels, $\mathrm{CC}$ genotype was significantly higher than $\mathrm{AA}$ in cases $(\mathrm{MD}=0.40,95 \% \mathrm{CI}: 0.06-0.73, \mathrm{P}=0.02$; Figure 7 ).

\section{Test of heterogeneity}

For the analyses of the serum lipid levels, the $I^{2}$ values of heterogeneity were greater than $50 \%$ and $\mathrm{P}$ values of

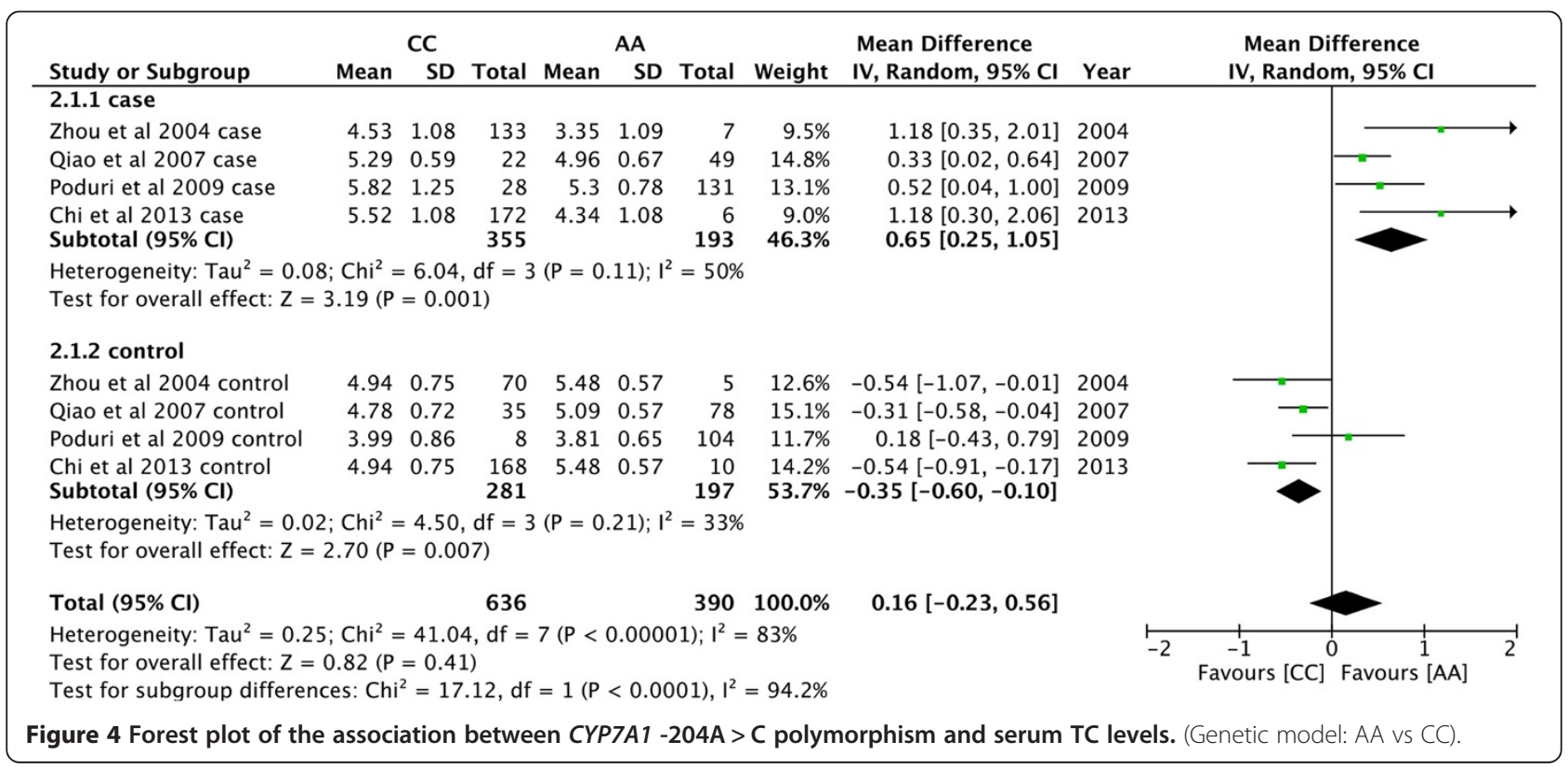




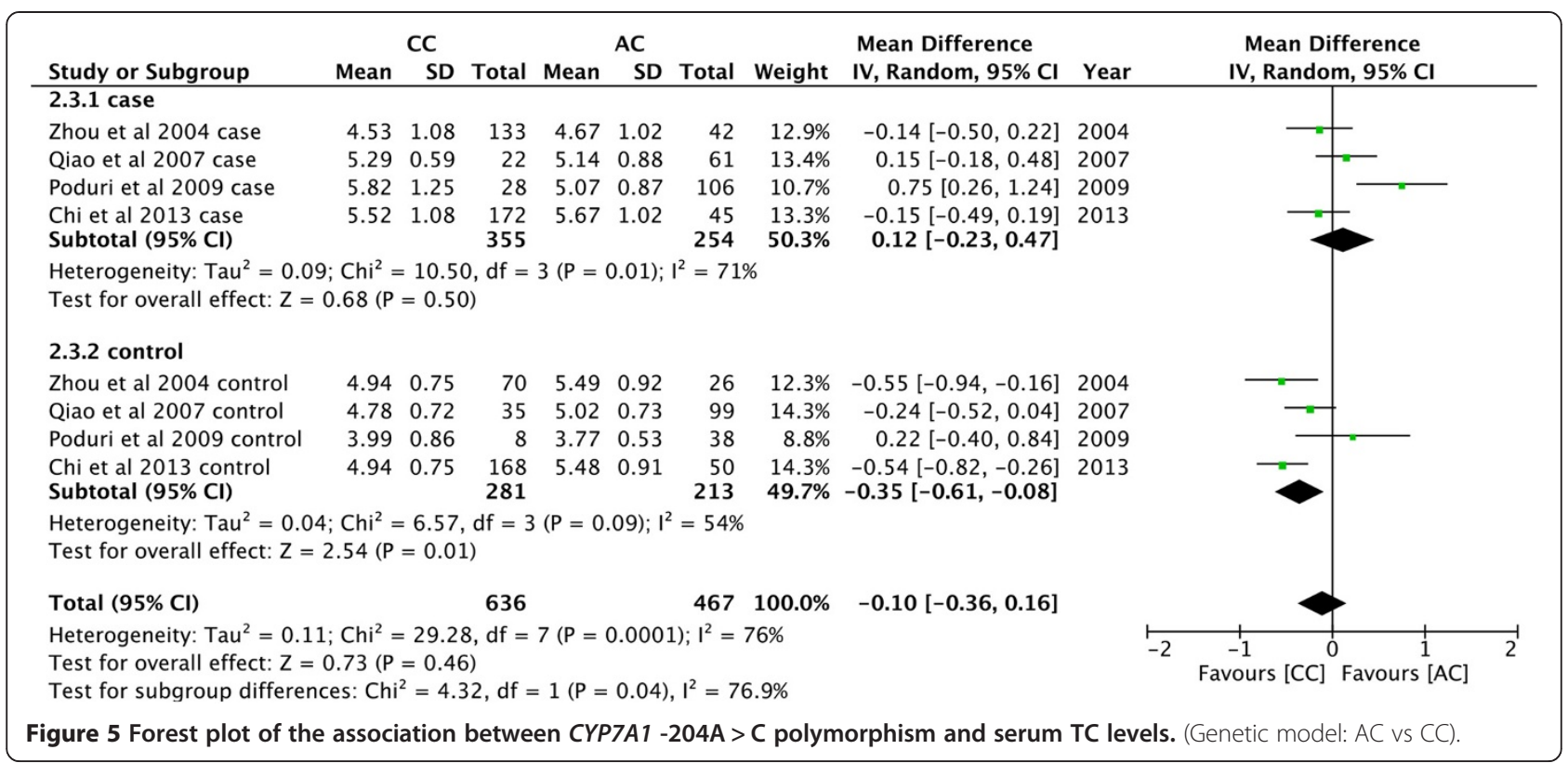

heterogeneity were less than 0.10 in all of the mentioned models above in the overall populations, indicating that significant between-study heterogeneity among the studies. In order to explore the possible sources of heterogeneity, we seperated the studies into cases and controls. Thereafter, the between-study heterogeneity was obviously reduced or even gone under the subgroup analyses.

\section{Discussion}

To our knowledge, this is the first meta-analysis to evaluate the association between CYP7A1 -204A > C polymorphism and GSD and serum lipid levels. In this study, we collected data from 9 papers to evaluate the association of CYP7A1 gene polymorphisms with GSD and serum lipid levels. The results showed that $-204 \mathrm{~A}>\mathrm{C}$ polymorphism of CYP7A1 gene related with difference in serum lipids. However, this polymorphism was not associated with GSD.

The -204A > C of CYP7A1 gene is one of the most frequently studied polymorphisms for the association with GSD. Our previous study showed that A allele of CYP7A1 gene might be considered as risk gene for GSD in Chinese patients [21]. Later on, Juzyszyn et al. [11] and Strivastava

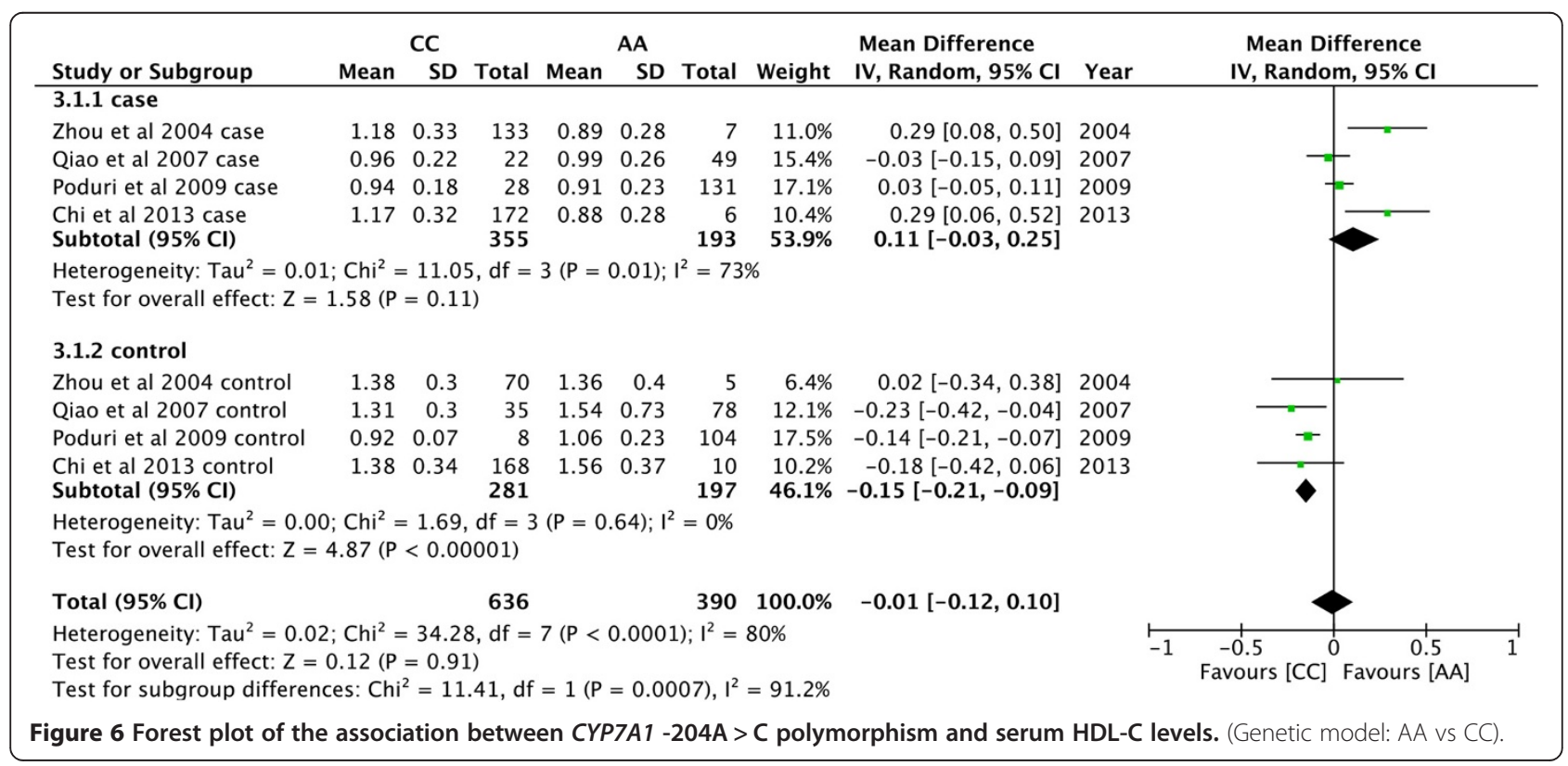




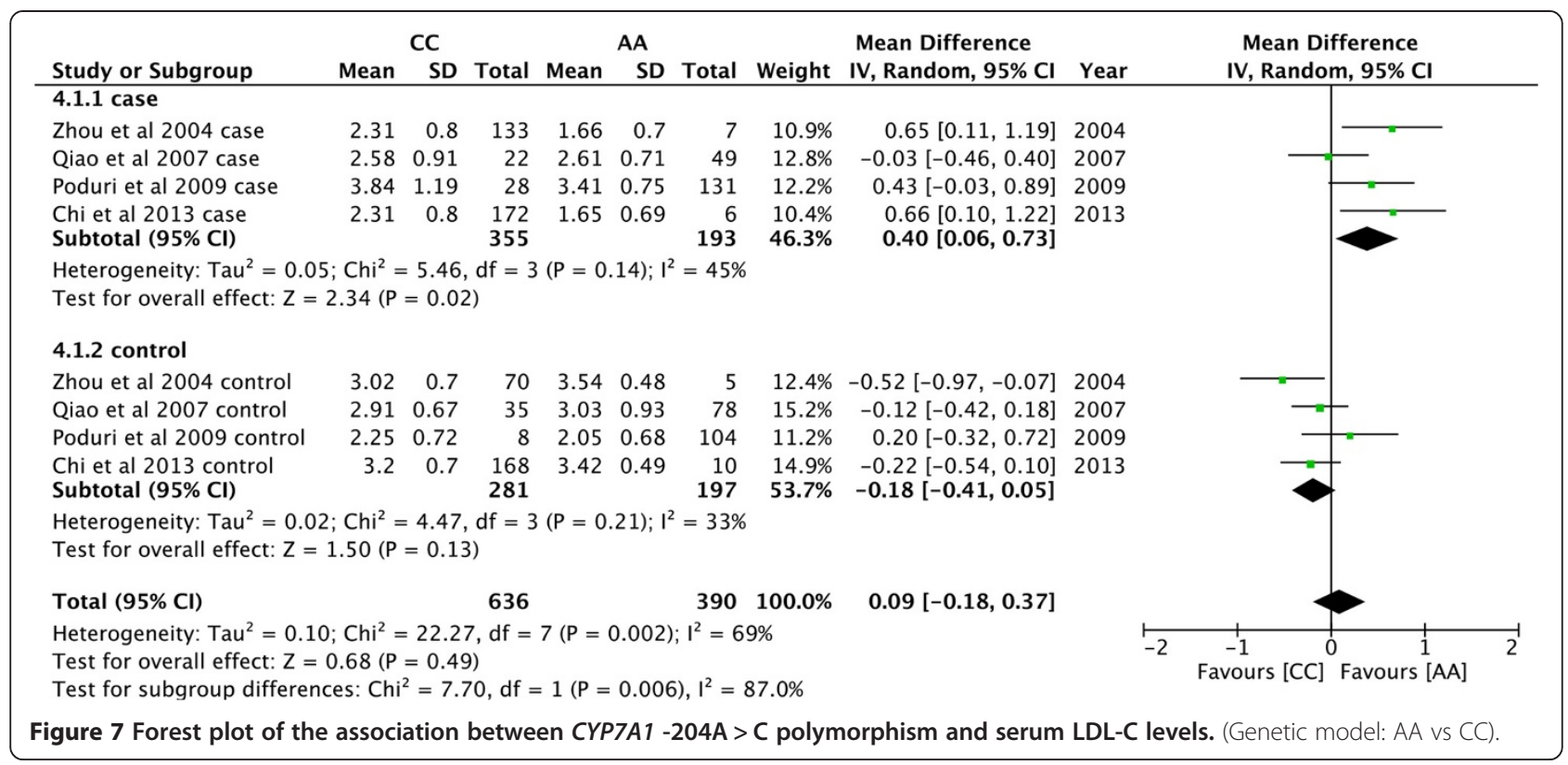

et al. [5], using larger samples from Polish and Indian, did not confirm such association. The samples sizes in the rest studies were relatively small $[12,23]$. Herein, by pooling all the previous studies, we demonstrated a lack of association between this polymorphism with GSD.

An obvious difference of gallstone prevalence between populations is present due to different ethnicities. GSD is highly prevalent in Pima Indians, Hispanic, relatively lower in Asian and the lowest in African [26]. The frequency of A allele of -204A > C polymorphism in gallstone-free subjects is lower in Asian population, 18.09\% in Chinese [23], high up to $60.2 \%$ in Indian [5]. In Caucasian population, its frequency is between 52.1 [11] and 72.28\% [12]. However, when the population was divided into Asian and Caucasian, we did not find any association of $-204 \mathrm{~A}>\mathrm{C}$ polymorphism with GSD existed in either ethnicity.

The second aim of our study is to evaluate the association between -204A > C polymorphism and serum lipids. The $-204 \mathrm{~A}>\mathrm{C}$ polymorphism was shown to be associated with plasma LDL-C concentrations [8,27]. Our previous study also found that individuals with A allele tended to have lower LDL-C concentrations [21]. While in this meta-analysis, we found that the genotype AA had significantly lower levels of LDL-C than genotype CC only in patients, but not in controls. Couture et al. [8] described that the genotype $\mathrm{AC}$ had significantly higher TG levels than the genotype $\mathrm{CC}$ in women and the $\mathrm{C}$ variant was also associated with an increased TC/HDL$\mathrm{C}$ ratio in men. Hofman et al. [10] found a significant $34 \%$ increase of serum TG levels in genotype AA as compared with genotype $\mathrm{CC}$ in a healthy normolipidaemic male population. However, our meta-analysis showed that genotype AC had higher TG levels than genotype AA, allele A carriers in healthy population had higher TC levels than genotype $\mathrm{CC}$, but not in the recessive models in cases, and genotype AA had higher HDL-C levels than genotype $\mathrm{CC}$ in controls.

Some limitations of this meta-analysis merit serious consideration. First, only the papers published in English and Chinese were included in our study. Any data reported in other languages could not be included which might bring some bias. Second, no adequate information such as source of the subjects, anti-dyslipidemia drug and etc. could be obtained in this meta-analysis. These factors might bring in several possible sources of heterogeneity. Third, most studies have recruited age $>40$ years, for whom environmental factors are likely to contribute more prominently than the genetic component during the development of GSD and dyslipidemia.

In conclusion, this meta-analysis did not found any association between CYP7A1 -204A > C polymorphism and GSD. However, this polymorphism was closely related with serum lipid levels.

\section{Additional file}

Additional file 1: Table S1. Supporting Information.

Competing interests

The authors have declared that no competing interests.

\section{Authors' contributions}

QC and ZQW collected the data and drafted the manuscript. QC and QC participated in the design of the study and performed the statistical analysis. ZYJ, EZC and CL conceived the study, participated in the design, and helped to draft the manuscript. All authors read and approved the final manuscript. 


\section{Acknowledgements}

This work was supported by grants from the Natural Science Foundation of China (No. 81070367 and No. 81270537). The funders had no role in study design, data collection and analysis, decision to publish, or preparation of the manuscript.

\section{Author details}

${ }^{1}$ Department of Surgery, Shanghai Institute of Digestive Surgery, Ruijin Hospital, Shanghai JiaoTong University School of Medicine, 200025 Shanghai, China. ${ }^{2}$ Department of Emergency, Ruijin Hospital, Shanghai JiaoTong University School of Medicine, 200025 Shanghai, China.

Received: 2 May 2014 Accepted: 29 July 2014

Published: 8 August 2014

\section{References}

1. Lammert F, Sauerbruch T: Mechanisms of disease: the genetic epidemiology of gallbladder stones. Nat Clin Pract Gastroenterol Hepatol 2005, 2:423-433.

2. Katsika D, Griibovski A, Einarsson C, Lammert F, Lichtenstein P, Marschall HU: Genetic and environmental influences on symptomatic gallstone disease: a Swedish study of 43,141 twin pairs. Hepatology 2005, 41:1138-1143

3. Wang DQ, Afdhal NH: Genetic analysis of cholesterol gallstone formation: searching for Lith (gallstone) genes. Curr Gastroenterol Rep 2004, 6:140-150.

4. Pullinger CR, Eng C, Salen G, Shefer S, Batta AK, Erickson SK, Verhagen A, Rivera CR, Mulvihill SJ, Malloy MJ: Human cholesterol 7a-hydroxylase (CYP7A1) deficiency has a hypercholesterolemic phenotype. J Clin Investig 2002, 110:109-117.

5. Srivastava A, Choudhuri G, Mittal B: CYP7A1 (-204 A > C; rs3808607 and $-469 \mathrm{~T}>\mathrm{C}$; rs3824260) promoter polymorphisms and risk of gallbladder cancer in North Indian population. Metabolism 2010, 59:767-773.

6. Shen J, Arnett DK, Parnell LD, Lai CQ, Straka RJ, Hopkins PN, An P, Feitosa MF, Ordovas JM: The effect of CYP7A1 polymorphisms on lipid responses to fenofibrate. J Cardiovasc Pharmacol 2012, 59:254-259.

7. De Castro-Oros I, Pampin S, Cofan M, Mozas P, Pinto X, Salas-Salvado J, Rodriguez-Rey JC, Ros E, Civeira F, Pocovi M: Promoter variant -204A > C of the cholesterol 7alpha-hydroxylase gene: association with response to plant sterols in humans and increased transcriptional activity in transfected HepG2 cells. Clin Nutr 2011, 30:239-246.

8. Couture P, Otvos JD, Cupples LA, Wilson PW, Schaefer EJ, Ordovas JM: Association of the A-204C polymorphism in the cholesterol 7ahydroxylase gene with variations in plasma low density lipoprotein cholesterol levels in the Framingham Offspring Study. J Lipid Res 1999 40:1883-1889.

9. Hubacek JA, Pitha J, Skodova Z, Poledne R, Lanska V, Waterworth DM, Humphries SE, Talmud PJ: Polymorphisms in CYP-7A1, not APOE, influence the change in plasma lipids in response to population dietary change in an 8 year follow-up; results from the Czech MONICA study. Clin Biochem 2003, 36:263-267

10. Hofman MK, Weggemans RM, Zock PL, Schouten EG, Katan MB, Princen HM: CYP7A1 A-278C polymorphism affects the response of plasma lipids after dietary cholesterol or cafestol interventions in humans. J Nutr 2004, 134:2200-2204.

11. Juzyszyn Z, Kurzawski M, Lener A, Modrzejewski A, Pawlik A, Drozdzik M: Cholesterol 7a-Hydrolase (CYP7A1) c.-278A > C Promoter Polymorphism in Gallstone Disease Patients. Genet Test 2008, 12:97-100.

12. Sanchez-Cuen J, Aguilar-Medina M, Arambula-Meraz E, Romero-Navarro J, Granados J, Sicairos-Medina L, Ramos-Payan R: ApoB-100, ApoE and CYP7A1 gene polymorphisms in Mexican patients with cholesterol gallstone disease. World J Gastroenterol 2010, 16:4685-4690.

13. Hegele RA, Wang J, Harris SB, Brunt JH, Young TK, Hanley AJ, Zinman B, Connelly PW, Anderson CM: Variable association between genetic variation in the CYP7 gene promoter and plasma lipoproteins in three Canadian populations. Atherosclerosis 2001, 154:579-587.

14. Egger M, Davey Smith G, Schneider M, Minder C: Bias in meta-analysis detected by a simple, graphical test. BMJ 1997, 315:629-634.

15. Higgins JP, Thompson SG, Deeks JJ, Altman DG: Measuring inconsistency in meta-analyses. BMJ 2003, 327:557-560
16. Higgins JP, Thompson SG: Quantifying heterogeneity in a meta-analysis. Stat Med 2002, 21:1539-1558.

17. Lau J, loannidis JP, Schmid CH: Quantitative synthesis in systematic reviews. Ann Intern Med 1997, 127:820-826.

18. DerSimonian R, Laird N: Meta-analysis in clinical trials. Control Clin Trials 1986, 7:177-188.

19. Mantel N, Haenszel W: Statistical aspects of the analysis of data from retrospective studies of disease. J Natl Cancer Inst 1959, 22:719-748.

20. Poduri A, Khullar M, Bahl A, Sharma YP, Talwar KK: A combination of proatherogenic single-nucleotide polymorphisms is associated with increased risk of coronary artery disease and myocardial infarction in Asian Indians. DNA Cell Biol 2009, 28:451-460.

21. Jiang $Z Y$, Han $T Q$, Suo GJ, Feng DX, Chen S, Cai XX, Jiang ZH, Shang J, Zhang Y, Jiang Y, Zhang SD: Polymorphisms at cholesterol 7alphahydroxylase, apolipoproteins $B$ and $E$ and low density lipoprotein receptor genes in patients with gallbladder stone disease. World $J$ Gastroenterol 2004, 10:1508-1512.

22. Chi J, Zhai CK, Guo YB, Zhang H, Han SF: [Influences of CYP7A1 gene polymorphism on hyperlipidemia in middle-aged and old populations] Zhongguo Gong Gong Wei Sheng 2013, 29:491-493.

23. Zhao Y, Yao YG: [Association of 7a-hydroxylase gene polymorphism with cholesterol cholecystolithiasis]. Zhongguo Pu Wai Ji Chu Yu Lin Chuang Zo Zhi 2010, 17:60-63.

24. Zhou B, Zhang S, Xiao C, Zhang K, Zhang L, Li G, Li P, Liu H, Zheng K: [Association of 7alpha-hydroxylase gene polymorphism with levels of plasma lipids]. Yi chuan = Hereditas/Zhongguo Yi Chuan Xue Hui Bian Ji 2004, 26:283-286.

25. Qiao Y, Liu R, Bai H, Liu Y, Li X, Tang CW, Liu BW: [Association between cholesterol 7alpha-hydroxylase -204A/C gene polymorphism and endogenous hypertriglyceridemia in Chinese]. Zhonghua Yi Xue Yi Chuan Xue Za Zhi 2007, 24:432-436.

26. Stinton LM, Shaffer EA: Epidemiology of gallbladder disease: cholelithiasis and cancer. Gut Liver 2012, 6:172-187.

27. Wang J, Freeman DJ, Grundy SM, Levine DM, Guerra R, Cohen JC: Linkage between cholesterol 7alpha-hydroxylase and high plasma low-density lipoprotein cholesterol concentrations. J Clin Invest 1998, 101:1283-1291.

\section{doi:10.1186/1476-511X-13-126}

Cite this article as: Cai et al:: Relationship between CYP7A1 -204A > C polymorphism with gallbladder stone disease and serum lipid levels: a meta-analysis. Lipids in Health and Disease 2014 13:126.

\section{Submit your next manuscript to BioMed Central and take full advantage of:}

- Convenient online submission

- Thorough peer review

- No space constraints or color figure charges

- Immediate publication on acceptance

- Inclusion in PubMed, CAS, Scopus and Google Scholar

- Research which is freely available for redistribution 